\title{
Paper methodology for pipe steels in hydrogen containing environments. Review
}

\author{
A.B. Arabey \\ Gazprom, St. Petersburg, Russia \\ V.A. Egorov, K.B. Konischev \& Semenov \\ Gazprom VNIIGAZ LLC, Moscow reg., Russia
}

\begin{abstract}
The review article provides test methods for pipe steels in environments containing hydrogen. The authors analyze test procedures designed for determination of pipe steel properties to provide further estimation of their serviceability for transmission of hydrogen-containing natural gas. The fatigue properties of the pipe metal decrease with increasing hydrogen content in the gas mixture. The method of determining the of the fatigue crack growth rate is promising for pipe metal in gas mixture containing hydrogen.It has been established that hydrogen impacts gas mixture compression. This fact should be taken into account when selecting operation modes for compressor stations.
\end{abstract}

Keywords: hydrogen embrittlement, hydrogen-methane gas mixture, fatigue damage, crack growth rate, strength properties

\section{INTRODUCTION}

Hydrogen can be considered as a clean energy carrier, similar to electricity (Nitsh \& Voigt, 1988), (Aksyutin et al., 2017). Using the existing natural gas (NG) grid for the hydrogen service has been being considered over the past decades.It has been found, that transporting hydrogen using an existing natural gas network is technically feasible (Bedel \& Junker, 2006). Existing gas transmission system (GTS) can be used for hydrogen-containing natural gas as well. Hydrogen embrittlement of carbon steels that the major pipelines are made of can impose restrictions on transmission of hydrogenmethane gas mixtures through GTS. Hydrogen embrittlement of steels has been investigated by a number of scientists (Nanninga et al., 2010), (Marhi \& Somerday, 2008), (Kolachev, 1985), (Nagumo, 2016). These studies analyze hydrogen impact only on metal that stays tensile enough after exposure to hydrogen. At the same time, most of metallic materials have reduced resistance to fatigue damage and high fatigue crack growth rate in hydrogen environments (Marhi \& Somerday, 2012). Changing the hydrogen concentration in the gas mixture leads to unsteady operation of the GTS (Guandalini et al., 2015). Recently, the American Society of Mechanical Engineers (ASME) has adopted a code specifically for hydrogen piping and pipelines: ASME Pressure Piping Code B31.12. Additionally, ASME has adopted new language in the Boiler and Pressure Vessel Code (Section VIII, Division 3, Article KD-10) for qualifying pressure vessels for hydrogen service. These rules can be adopted for pipelines as well, as part of a fitnessfor-service management program (Baek et al., 2017). This work is motivated by a desire to describe the approach of fracture mechanics to serviceability for pipelines distributing mixed hydrogen and natural gas. 


\section{MATERIAL AND TEST METHODS}

A hydraulic servo controlled testing machine Instron with an autoclave was used to measure the mechanical properties of specimens in mixtures natural gas and hydrogen (ASTM G1422016). Chamber material is insensitive to hydrogen embrittlement and is able to resist up to 20 $\mathrm{MPa}$ gaseous hydrogen pressure. Tests were conducted with API-5L X80 pipe samples (Figure 1) (ASTM G142 2016), (ASTM E647 2000).

Mechanical properties of the pipe metal have been determined by standard specimens. Fatigue crack growth tests have been carried out within this study on the compact tension specimens in accordance with (ISO 7539-6 2018).

Test environment: hydrogen-methane gas mixture with hydrogen content varying from $0 \%$ to $50 \%$. Tests have been performed under $12 \mathrm{MPa}$. For safety reasons methane was replaced by nitrogen.

\section{TEST RESULTS}

Authors (Meng et al., 2017) were determined that the change in hydrogen content in gas mixture didn't influence tensile properties (Figure 2).

The influence of added hydrogen on tensile behavior of thesmooth specimens is shown in Figure 3.

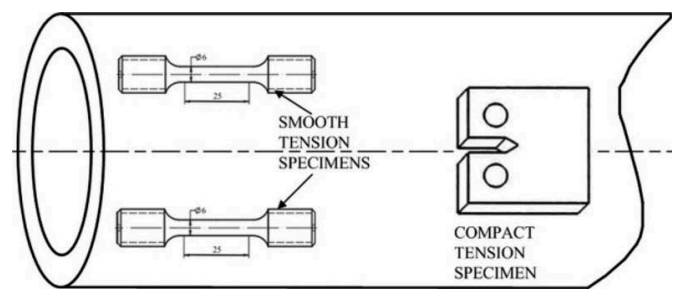

Figure 1. Specimens for tests from API-5L X80 pipe.

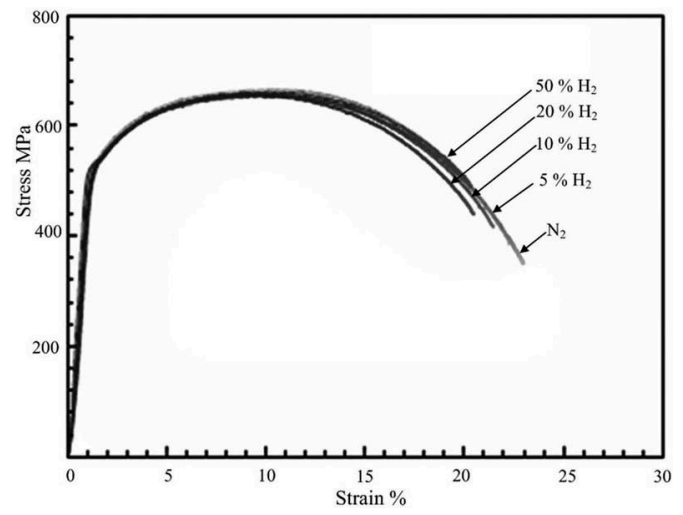

Figure 2. Influence of added hydrogen on the tensile of the smooth tension specimens. 


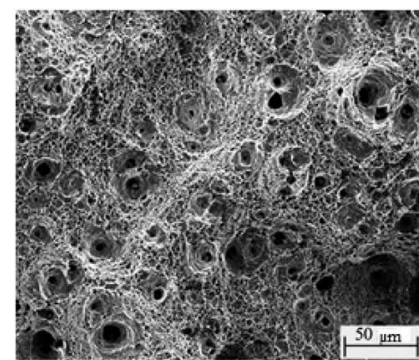

a)

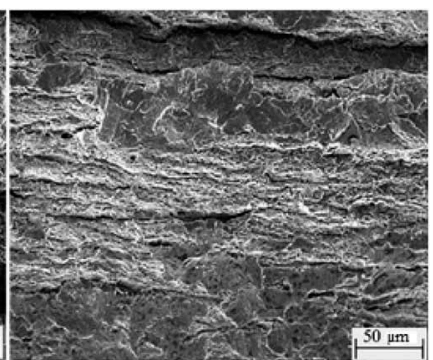

b)

Figure 3. Fractured surfaces of the smooth specimens in: a) nitrogen and; b) hydrogen blend $20 \%$.

The reduction of area specimens and hydrogen embrittlement index is calculated as follows:

$$
\begin{gathered}
R_{A}=1-\left(S_{k} / S_{0}\right) \\
E_{I}(\%)=\frac{R_{A}^{N_{2}}-R_{A}^{H_{2}}}{R_{A}^{N_{2}}} \times 100
\end{gathered}
$$

where $R_{A}=$ the reduction of area specimen in $\mathrm{N}_{2}$ and $\mathrm{H}_{2}$ blends; $S_{k}=$ cross-section area of the specimen after failure; $S_{0}=$ cross-section area of the specimen before failure; $E_{I}=$ specimen hydrogen embrittlement index $\left(E_{I}=0\right.$ means no hydrogen embrittlement $E_{I}=100 \%$ is value for maximum embrittlement).

The indexes for various hydrogen blends are shown in Table 1.

Authors (Meng et al., 2017) have suggested that gaseous hydrogen content increasing in gas mixture from $0 \%$ to $50 \%$ results in metal embrittlement of high-strength API-5L X80 pipes. Fatigue crack growth rate escalates by an order of magnitude when moving from neutral nitrogen to gaseous mixtures of nitrogen and hydrogen. Fatigue crack growth rate also builds up with hydrogen content increase in gas mixture from $5 \%$ to $50 \%$. Simultaneous hydrogen exposure and mechanical loads on pipe steel can lead to hydrogen embrittlement. For this reason there is a need to understand the problem of reversed pipeline loads in hydrogencontaining environments. The influence of cyclic loads on crack growth rate of API-5L X80 pipe steel in pure nitrogen and hydrogen blends is shown in Figure 4.

The effect of hydrogen on the properties of API-5L X80 was investigated by similar methods (Briottet et al., 2011). It has been established that «fatigue crack growth rate» parameter is more sensitive to alternation of hydrogen content, than to any changes in mechanical properties of pipe steel. For air and hydrogen environments fatigue crack growth rates in shown in Figure 5.

The fatigue crack growth rate increases by at least an order of magnitude in hydrogen compared to air. This difference explained by interaction between hydrogen and dislocations in API-5L X80 steel.

Specialists of the Institute of Standards and Technologies (the USA) were engaged in the study of hydrogen embrittlement and simulated fatigue crack growth processes on API-5L

Table 1. Hydrogen embrittlement of API-5L X80 steel.

\begin{tabular}{llllll}
\hline $\mathrm{H}_{2}$ content, $\%$ & 0 & 5 & 10 & 20 & 50 \\
\hline $\mathrm{E}_{\mathrm{I}}$ index, $\%$ & 0 & 3,39 & 4,32 & 15,88 & 16,77 \\
\hline
\end{tabular}




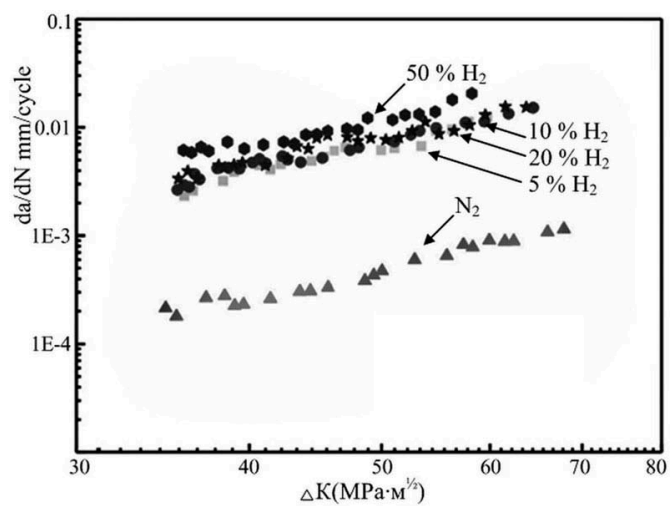

Figure 4. $\mathrm{Da} / \mathrm{dN}$ versus $\Delta \mathrm{K}$ curves in nitrogen gas and hydrogen blends.

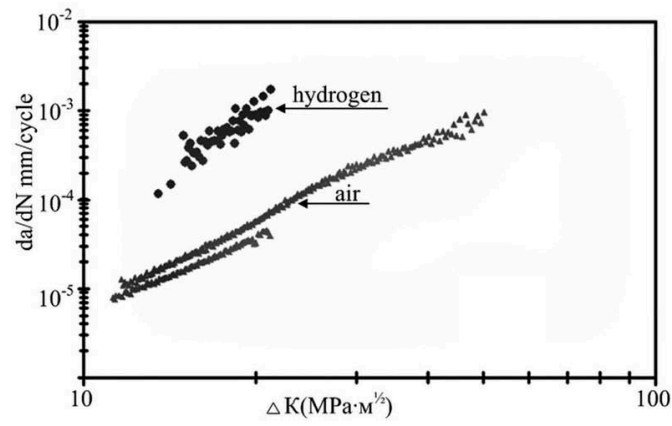

Figure 5. Fatigue crack growth rate behavior in air and hydrogen gas.

X100 steel (Amaro et al., 2014). Studies have shown that the fatigue crack growth rate in air and in environments with different hydrogen pressure varied (Figure 6).

Authors determined that fatigue crack growth rate depended on hydrogen content. Upgrading of hydrogen pressure from 1.72 MPa to $20.68 \mathrm{MPa}$ can double the growth rate.

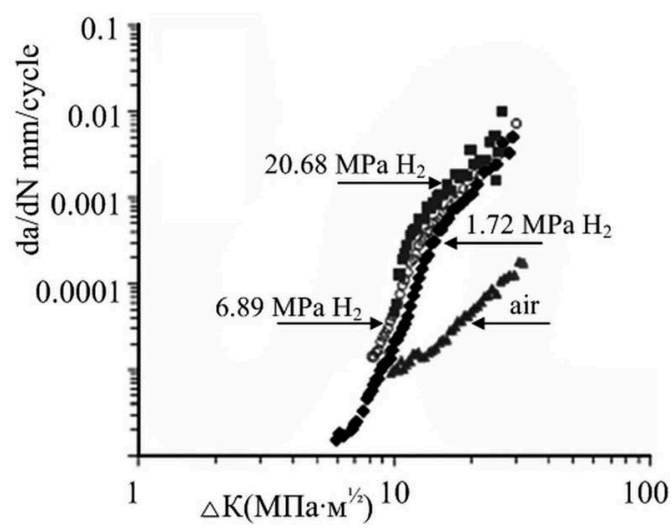

Figure 6. Fatigue crack growth rate behavior in air and hydrogen gas. 


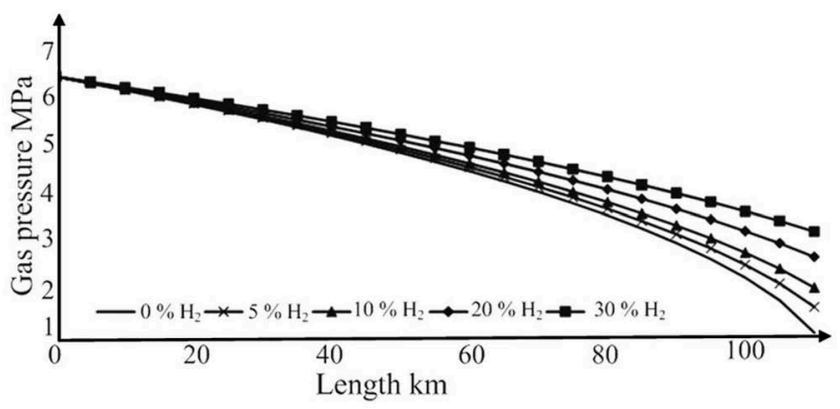

Figure 7. Gas pressure drop in pipeline for different hydrogen fractions in mixture with natural gas.

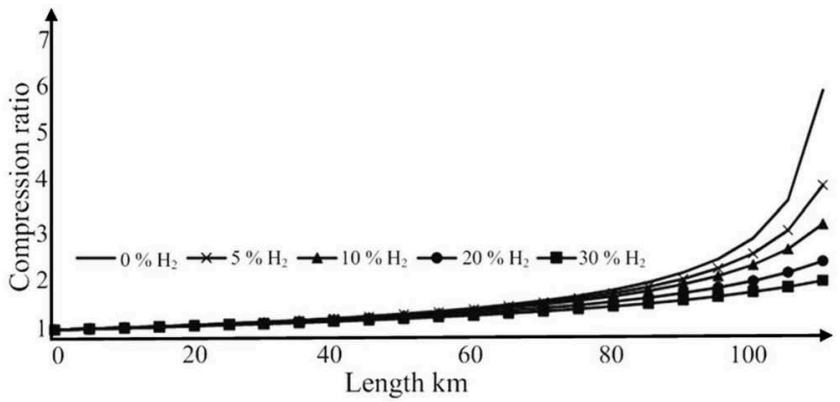

Figure 8. Compression ratio for mixture gas depending from the pipeline length.

In addition to pipes, compressor station, belong to GTS. Therefore, should be paid attention to physic parameters hydrogen transportation by pipeline GTS (Zabrzeski et al., 2017). For example hydrogen is much less viscous, and thus it can decrease Joule-Thompson effect in terms of pressure drop (Shimko, 2005). A mixture of natural gas and hydrogen in the pipeline $600 \mathrm{~mm}$ was investigated. The hydrogen content in natural gas modified from $0 \%$ to $30 \%$. The gas temperature was to be $7^{\circ} \mathrm{C}$ and initial gas pressure 6.4 MPa (Zabrzeski et al., 2019). Correlation between gas pressure, hydrogen content and pipeline length is shown in Figure 7.

Simulated conditions for hydrogen-containing natural gas transmission through existing GTS must take into account operation of compressor stations. Figure 8 shows relationship of compression and the length of a pipeline that transmits hydrogen-containing natural gas.

Thus, hydrogen strongly influences variation of the process of natural gas compression.

\section{CONCLUSIONS}

Increase in hydrogen content in gas mixtures from $5 \%$ to $50 \%$ does not have significant impact on traditional mechanical properties of high-strength API-5L X80 pipe steels. Variation of fatigue crack growth rate depends on hydrogen content in pipe steel and is sensitive to the level of hydrogen content in metal. Fatigue crack growth rate determination method can be prospective in terms of selection of the best chemical composition of the pipe steel that is not exposed to negative hydrocarbon impact during transmission of methane-hydrogen mixtures.It is necessary to give consideration to physical properties of hydrogen when selecting compression and transmission modes for methane-hydrogen mixtures via existing GTS. 


\section{REFERENCES}

Aksyutin O.E., Ishkov A.G., Romanov K.V., Teterevlev R.V., Khloptsov V.G., Kazaryan V.A., Stolyarevsky A. Ya. Power content of methane-hydrogen fuel under the conditions of transition to lowcarbon economy. Gazovaya promyshlennost = Gas industry. Special edition №1/750/2017, 82-85.

Amaro R.L., Rustagi N., Findley K.O., Drexler E.S., Slifka A.J. Modeling the fatigue crack growth of X100 pipeline steel in gaseous hydrogen. International Journal of Fatigue 59 (2014) 262-271.

ASTM E647-00 Standard test method for measurement of fatigue crack growth rates.

ASTM G142-2016 Standard test method for determination of metals to embrittlement in hydrogen containing environments at high pressure, high temperature, or both.

Baek U.B., Nahm S.H. Kim W.S. Ronevich, J.A. and San M. Compatibility and suitability of existing steel pipelines for transport of hydrogen-natural gasblendshttps://hysafe.info/wp-content/uploads/ 2017_papers/228.pdf

Bedel L., Junker M. Naturel gas pipelines for hydrogen transportation WHEC 16/ 13-16June 2006-Lyon France.

Briottet L., Moro I., Lemoine, P. Quantifying the hydrogen embrittlement of pipe steel for safety considerations. Available from: http://conference.ing.unipi.it/ichs2011/papers/186.pdf

Guandalini G., Colbertaldo P., Campanari S. Dynamic Quality Tracking of Natural Gas and Hydrogen Mixture in a Portion of Natural Gas Grid Energy Procedia 75 (2015) 1037-1043.

ISO 7539-6:2018 Corrosion of metals and alloys-Stress corrosion testing-Part 6: Preparation and use of pre-cracking specimens for tests under constant load or constant load or constant.

Kolachev B.A. Hydrogen embrittlement of metals. Moscow. Metallurgy. 1985.

Marhi C.S. and Somerday B.P. Technical reference on hydrogen compatibility of materials: plain carbon ferritic steels: C-Mn alloys. Sandia National Laboratories Report No. SAND2008-1163.

Marhi C.S. and Somerday B.P. Technical reference on hydrogen compatibility of materials. Sandia National Laboratories Report No. SAND2012-7321, Livermore CA, 2012.

Meng B., Gu C., Zhang L., Zhou C., Li X., Zhao Y., Zheng J., Chen X., Han Y. Hydrogen effects on X80 pipeline steel in high-pressure natural gas/hydrogen mixtures. International Journal of Hydrogen Energy 42(2017) 7404-7412.

Nagumo M., Fundamentals of hydrogen embrittlement ISBN 978-981-10-0160-4, 2016.

Nanninga N.E., Slifka A.J., Levy Y.S. and White C. A review of fatigue crack growth for pipeline steels exposed to hydrogen. Journal of Research of the National Institute of Standards and Technology, 115 No.6, 2010, 437-452.

Nitsh J. and Voigt C. Launch concepts for non-fossil hydrogen, 1988, Springer, Berlin.

Shimko M.A. V.E.1 Combined Reverse-Brayton Joule Thompson hydrogen liquefaction cycle. Available from: http://www.hydrogen.energy.gov/pdfs/progress05/v_e_1_shimko.pdf

Zabrzeski Ł., Janusz P., Liszka K., Laciak M. and Szurlej A. The effect of hydrogen transported through gas pipeline on the functioning of gas compression station work AGH Drilling, Oil, Gas 2017/34.

Zabrzeski L., Janusz1 P., Liszka K., Laciak M., Szurlej A. Hydrogen-natural gas mixture compression in case of transporting through high-pressure gas pipelines. Available from: https://iopsciennce.iop.org/ article/10.1088/1755-1315/214/1/012137/pdf 